\title{
APRESENTACÃO
}

\section{Fabíola Rohden*}

\section{Universidade Federal do Rio Grande do Sul - Brasil}

Jane A. Russo**

Universidade do Estado do Rio de Janeiro - Brasil

\author{
Alejandra Roca ${ }^{* * *}$ \\ Universidad de Buenos Aires - Argentina
}

Este número de Horizontes Antropológicos dedicado ao tema "Gênero e sexualidade, saberes e intervenções" pretendeu abrir espaço para artigos que se dedicassem a discutir as articulações possíveis entre a produção de variadas formas de conhecimento e seus efeitos no cotidiano. Nesse sentido, a proposta foi compor um dossiê que agregasse diferentes perspectivas teóricas e campos de investigação empírica que refletissem sobre a produção de saberes e/ou distintas tecnologias de intervenção relacionadas com gênero e sexualidade, na interseção com outros marcadores sociais da diferença, dentro do recorte mais amplo das pesquisas sobre corpo e saúde. A intenção era priorizar as interfaces entre ciências, tecnologias, sociedade e poder, tendo como foco as análises relativas às redes que envolvem desde a produção de conhecimentos até suas repercussões relacionadas a novas formas de entendimento do sujeito em diversos cenários contemporâneos, incluindo os recentes processos de (bio)medicalização em curso e o surgimento de distintas formas de (bios)sociabilidade e subjetividades.

Por um lado, essa proposta poderia parecer demasiadamente aberta a um campo de estudos muito amplo, pretendendo dar conta do vasto leque

\footnotetext{
* Contato: fabiola.rohden@gmail.com

** Contato: jane.russo@gmail.com

*** Contato: roca.ale@gmail.com
} 
de trabalhos acadêmicos sobre gênero e sexualidade, cujo crescimento nas últimas décadas tem sido exponencial, só comparável ao aumento de sua relevância no cenário político atual. Tal tarefa seria por si só inviável na medida em que certamente não teríamos espaço para acolher tantos e tão distintos trabalhos. Dentro desse campo maior de estudos em gênero e sexualidade vem se assistindo a um crescimento singular, no Brasil e no cenário internacional, de investigações mais especializadas que privilegiam as interfaces entre corpo, gênero e sexualidade e a produção de conhecimentos e intervenções. Apostamos nesse recorte para compor este dossiê temático.

Nesse contexto, é necessário lembrar o modo como o Grupo de Trabalho (GT) "Corpo, saúde e doença", inicialmente organizado por Luiz Fernando Duarte e Ondina Fachel Leal no âmbito da Associação Nacional de PósGraduação em Ciências Sociais (Anpocs), foi fundamental para a constituição de um campo de reflexão em torno das práticas e intervenções sobre o corpo e o gênero entre cientistas sociais no Brasil. Uma série de GTs e mesas-redondas em encontros da Associação Brasileira de Antropologia (ABA) e Reuniões de Antropologia do Mercosul (RAM) desde a segunda metade dos anos 1990 também contribuíram fortemente para a constituição dessa área temática. Já nos anos 2000, as Reuniões de Antropologia da Ciência e Tecnologia (ReACT) trouxeram um conjunto de novas questões que fundamentaram etnografias originais e inovadoras, além de novos aportes teóricos para as discussões sempre candentes em torno do pares biológico/social e natural/cultural. No cenário internacional e, em particular, latino-americano, esses debates têm constituído eixos reflexivos fundamentais para a produção de novas redes de pesquisa e interlocução.

O conjunto significativo de trabalhos recebidos para esta publicação expressou a multiplicidade no entendimento das interfaces pretendidas na proposta deste número, assim como o amadurecimento teórico e a riqueza das investigações empíricas que vêm sendo realizadas. Neste volume, tentamos retratar, por meio dos artigos selecionados, essa diversidade de abordagens.

Se considerarmos meramente os temas elencados, seria difícil conceber aproximações possíveis entre os trabalhos. Saúde e aprimoramento, testosterona e desejo sexual, implantes subcutâneos, hormônios sexuais, "embelezamento íntimo", gerontologia LGBT, performance esportiva, aprendizagem na prostituição, trajetórias de pessoas trans, contracepção de emergência, e pentecostais no Congresso Nacional são objetos que indicam um cenário de 
interesses bem variado. Sem dúvida é possível identificar logo de imediato uma preeminência do foco nos saberes e intervenções biomédicos. Contudo, é interessante poder agregar a esse foco a atenção crítica dada a outras formas de produção de conhecimento e suas consequências.

Esse contraponto, inclusive, nos leva a pensar sobre o privilégio político e analítico dado ao saber biomédico ou aos chamados saberes científicos em nossa sociedade. Da mesma forma, nos leva a indagar de modo mais amplo acerca dos contrastes possíveis entre diferentes tipos de saberes, em termos de legitimidade, reconhecimento, força política, moralidades envolvidas, etc. Nessa direção, cabe nos perguntarmos acerca de quais saberes e intervenções são considerados legítimos, e em quais contextos. Melhor dizendo, como as concepções acerca das diferenças de gênero, sexualidade, geração, etnia, classe social, religião impactam o conteúdo e a autoridade dos diferentes tipos de conhecimento. Portanto, não se trata simplesmente de pensar acerca de quem está na posição de produzir conhecimento, mas, de forma mais elaborada, da complexidade envolvida na inter-relação entre essas dimensões e as lógicas que lhes são próprias.

Outra linha de questões que surge se refere aos limites do corpo ou da biologia concebidos como intransponíveis. Novamente aqui, a amplitude dos exemplos trazidos nos artigos nos permite discutir a variação em torno desses limites, já que se percebe que essas fronteiras são construídas diferencialmente dependendo de para quem, como, ou em que contextos estão sendo aplicadas ou diluídas. Além disso, estão associadas aos padrões morais que vão se redesenhando e atualizando em distintos cenários. Padrões como o do corpo belo, jovem, saudável, do sujeito sexualmente ativo, heterossexual, bem definido dicotomicamente em termos de gênero.

\section{Gênero, sexualidade e ciência como perspectiva analítica e crítica}

A possibilidade de encampar esses questionamentos tem feito parte, e em certa medida é decorrente, da trajetória dos estudos que têm se focado na articulação entre gênero e ciência a partir de uma ótica feminista, que merece ser enfatizada nesse contexto. Essa longa e produtiva linha de trabalhos tem se caracterizado por enfrentar muito enfaticamente o engodo da separação natureza/cultura que havia deixado muitas/os estudiosas/os do gênero e da 
sexualidade relegadas/os à compreensão do que seria tomado de forma banal como uma mera construção social. A capacidade de questionar essa divisão e reivindicar o estudo também daquilo que era a princípio resguardado às disciplinas biológicas ajudou a fomentar um novo debate. Era preciso não só dar conta de estudar o que era definido como a biologia, o corpo, a natureza, mas também pôr em xeque a própria distinção. E para fazer isso, tornava-se fundamental o investimento em investigações que pudessem analisar as próprias ciências biológicas e biomédicas, ou ditas naturais, a partir de dentro, por meio do estudo das suas próprias lógicas, conceitos, vocabulário, etc. Não é à toa que um importante conjunto de autoras desse campo veio de uma formação inicial nas ciências naturais e caracterizou seu percurso acadêmico pela incorporação das críticas feministas à ciência. Conhecidas como biólogas feministas - Haraway (1995), Fausto-Sterling (1992), Bleier (1997), Birke (1986), Oudshoorn (1994), entre outras - fizeram parte de uma das primeiras gerações de mulheres cientistas que voltaram sua atenção para a produção do conhecimento biológico acerca das diferenças entre os sexos e para o modo como tal conhecimento se sustenta na própria hierarquia de gênero. Partindo de uma visão crítica do conhecimento produzido no âmbito das ciências da natureza, chegaram à crítica da produção do conhecimento científico em si, na medida em que as definições acerca do que investigar e de como fazê-lo estavam desde sempre comprometidas com uma visão de mundo "generificada".

De fato, além da já mencionada sagacidade em problematizar a dicotomia natureza/cultura, talvez o principal ponto que distingue a linha de discussão iniciada pelas "biólogas feministas", muitas vezes antes ou com muito maior ênfase que outros autores dos estudos sociais da ciência, tem sido a robustez de seu empreendimento crítico. Longe de uma simples contextualização da produção do conhecimento em decorrência das contingências sociais e das marcas de gênero, o que está fortemente em cena é uma crítica à própria epistemologia, ao conteúdo e mesmo ao projeto científico moderno. As abordagens podem variar imensamente, mas o que se tem em comum é a imprescindível necessidade de reconhecer a produção de conhecimento por meio de sua dimensão política. Ou, na linha de argumentação de Jasanoff (2004), torna-se necessário lançar mão de instrumentos e noções como o argumento de coprodução entre ciência, política, sociedade e todas as implicações decorrentes dessa indissociabilidade. A ciência, portanto, não está à parte ou imune aos constrangimentos sociais, mas é decorrente deles. E como já apontava 
Fleck (2010) nos anos 1930, poderia ser concebida como mais legítima na medida em que mais incorporasse seriamente ou criticamente essas demandas. Não se trata, assim, de assumir uma posição acusatória ou depreciativa da ciência, mas de levar em conta mais seriamente o seu papel em nossa sociedade. ${ }^{1}$ Nos termos de Haraway (1995), por exemplo, trata-se de levar às últimas consequências a reflexão sobre o que pode ser uma objetividade científica, enraizada nos compromissos éticos que necessariamente tem.

Essa ordem de reflexões incide diretamente na forma pela qual concebemos o conhecimento científico, mas também é útil para pensarmos sobre outras produções de saberes e intervenções produzidas por exemplo no campo religioso, no campo jurídico ou em outros campos profissionais diversos. Permite que possamos compreender esses sistemas de regras, valores, orientações, condutas desde uma perspectiva mais simétrica por meio da qual o conteúdo e a posição ocupada precisam ser constantemente e complexamente contextualizados. São sempre saberes e intervenções em construção e em disputa e que a cada situação têm que ser descritos com profundidade analítica. Não pode haver mais lugar, por exemplo, para determinismos explicativos de qualquer ordem, como aqueles baseados na distinção natureza/cultura. Mas ao contrário, essas próprias explicações tornam-se alvos de investimento crítico.

É preciso dizer que esse tipo de percepção analítica em muito tem a ver, no campo dos estudos sobre corpo, gênero e sexualidade, com a imprescindível necessidade, evidente em tantas etnografias, de atentar para e pôr em relevo a fluidez das práticas das pessoas em suas vidas concretas, muitas vezes em contraste com a dureza das doutrinas tradicionalmente ou oficialmente estabelecidas. Essa atenção às práticas tanto nos leva, portanto, a entender como gênero e sexualidade são constantemente produzidos ou performados (Butler, 1993) por meio de atualizações constantes e quotidianas quanto nos permite pensar acerca de como distintos saberes também são fruto desse tipo de processos. Não há como conceber nem na biomedicina ou no sistema jurídico, por exemplo, um conhecimento plenamente estabilizado ou inquestionável, já que antigas e novas controvérsias podem sempre entrar em cena. Certamente há distinções hierárquicas entre o que está mais legitimamente estabelecido,

\footnotetext{
1 Para uma discussão mais extensa acerca desse ponto, na qual se propõe uma distinção analítica entre as ciências empíricas que etnografamos e o estatuto da grande Ciência, como fonte de verdade e autoridade no cenário moderno, ver Rohden et al. (2016).
} 
mas, nesse caso, é preciso compreender exatamente como é possível que essa posição se mantenha, indagando sobre os jogos de força que estão atuando em diferentes direções. No nosso caso específico, cabe nos perguntarmos sobre quais vetores relativos a concepções de gênero e sexualidade estão sendo acionados e em quais direções na produção desses saberes e intervenções. Temos, portanto, enfatizado a dimensão política e prática da produção de conhecimentos e suas articulações com efeitos desiguais nos corpos, subjetividades, identidades, direitos.

Uma outra dimensão que merece ser destacada diz respeito mais especificamente ao fato de que quanto mais atentamos para as práticas, mais enfaticamente percebemos a impossibilidade da manutenção de fronteiras rígidas calcadas na velha divisão natureza/cultura. Quando investigamos o uso de fármacos, intervenções cirúrgicas e outros vários procedimentos biomédicos ou de outro tipo sobre os corpos e nos indagamos acerca de sua conexão com a produção de subjetividades ou de pertencimentos identitários de várias ordens, torna-se evidente a impossibilidade de demarcar esses limites. Nesse ponto é importante chamar a atenção para a sintonia com um movimento mais geral na antropologia, mas também em vários outros campos disciplinares especialmente inspirados pela teoria feminista, que tem renovado o debate acerca dessas questões. Quando se discute atualmente o caráter equivocado de análises que tomam como ponto de partida a fronteira entre corpo e biologia por um lado e subjetividade e cultura por outro, não se está pretendendo assumir uma posição que privilegie a percepção de um dos "lados", caindo novamente em um determinismo biologizante ou culturalista. O que está em jogo é a construção de uma perspectiva que leve a sério por exemplo a importância da produção de distintas materialidades, que por sua vez não fazem sentido ou não existiriam sem o inextrincável enredamento em um determinado contexto de relacionalidades. É exatamente nessa direção que perspectivas analíticas como as de Law e Mol (2002) e Mol e Law (2004) têm se tornado tão relevantes ao apontar para a necessária consideração de um materialismo sempre relacional e para conexão intransponível entre ontologias e políticas. ${ }^{2}$

2 Ver também Mol (1999, 2002), Law (2004) e ainda Abrahamsson et al. (2015) para uma crítica mais recente a análises materialistas que não consideram suficientemente os contextos relacionais. 
Essa perspectiva tem se tornado um horizonte de diálogo fundamental, especialmente para quem trabalha com gênero, sexualidade e ciência. Muito mais no sentido do conjunto de questões que tem imposto do que na conformação de soluções analíticas mais ou menos definitivas. Nos estudos concretos, ainda estamos caminhando para descobrir formas de investigação que possam dar conta de pensar, por exemplo, nos efeitos dos hormônios, considerando seriamente sua capacidade de ação, ao mesmo tempo em que prosseguimos na análise crítica que tem privilegiado a força e a autoridade do discurso biomédico e sua incorporação na vida diária das pessoas. Da mesma forma, cada vez mais vamos nos dando conta de que muitas vezes o próprio vocabulário antropológico que compartilhamos precisa ser revisto. Se seguimos em direção à consideração da ineficácia de tomar as dicotomias como ponto de partida, torna-se urgente a atenção crítica aos nossos próprios discursos e a busca por uma linguagem mais adequada. Voltando ao caso dos hormônios, para ilustrar esse ponto, podemos questionar se pensar em termos de efeitos subjetivos da materialidade dos hormônios não seria já partir de uma divisão que situa a subjetividade para além do que pode ser concebido como material. Não há dúvida de que estamos tratando de materialidades diversas aqui e essa heterogeneidade precisa ser atentamente problematizada. Porém, estamos tentando ressaltar como a reflexividade presente no campo hoje nos leva a desdobrar esse tipo de indagações, enfrentando o desafio de colocar nossos costumeiros pontos de partida, e de apoio, em xeque.

Cabe ressaltar, por outro lado, que a antropologia sempre esteve às voltas com esse universo de discussões e o que se produz atualmente está enraizado nessa longa trajetória reflexiva. Contudo, é importante situar a passagem para o surgimento de novas gamas de questões teóricas, que por sua vez também estão embasadas em novos problemas empíricos. Nessa direção, torna-se mais evidente a busca por inspirações teórico-metodológicas afinadas com a forma de proposição de problemas que ora se manifestam. Evidentemente, em função das considerações que temos feito, teoria e método só podem ser concebidos como plenamente interconectados. E na procura por formas de entendimento dos saberes e intervenções enquanto variadas possibilidades de manifestações performativas de gênero e sexualidade, as orientações metodológicas também passam por questionamentos e redefinições, no sentido de dar conta de diferentes tipos de práticas e materializações. 
É nesse sentido que reconhecemos a centralidade assumida por algumas abordagens, como a que vem sendo elaborada por Haraway (2004) ao longo das últimas décadas. A escolha pela menção a essa autora, para além do seu manifesto reconhecimento, se deve ao fato de que tem desenvolvido uma perspectiva de crítica feminista à ciência que tem se mantido plenamente atual e atravessado gerações. E uma de suas contribuições mais fundamentais tem sido exatamente na direção de problematizar as dicotomias e propor novos operadores conceituais. A noção de atores materiais semióticos ilustra perfeitamente a adoção de um artefato analítico que pretende romper com a possibilidade de separação entre o que seria da ordem material e da ordem linguística ou do significado. Para a autora, corpos e significados são produzidos ou materializados provisoriamente em virtude de suas interações no mundo e em função dessa ordem de interferências e fronteiras instáveis é que devem ser analisados (Haraway, 1995, p. 41).

$\mathrm{Na}$ esteira das contribuições de Haraway, uma série de novos trabalhos têm sido realizados, justamente tentando fugir das perspectivas dualistas. ${ }^{3}$ A título de ilustração, podemos citar a contribuição de Barad (2003, 2007), que tem se tornado uma das autoras cuja obra tem ganhado cada vez mais evidência. Novamente aqui a atenção às práticas e às performatividades é central e leva a autora a reconhecer que não se podem definir fronteiras a priori entre os chamados fatores materiais e discursivos, sociais e científicos, humanos e não humanos, naturais e culturais. É preciso pensar em termos de jogos de interferência e conceber agência e historicidade não só à linguagem e à cultura, mas também à matéria que, dessa forma, não pode ser tratada como passiva e imutável. Na direção de priorizar um "realismo agencial", a autora elabora o conceito de "intra-ação", que serviria para dar conta da impossibilidade de demarcar fronteiras precisas ou entidades separadas para além da existência de um determinado "fenômeno", outro conceito central. As intra-ações é que performam as próprias entidades e portanto suas fronteiras, sempre locais e provisórias, no contexto de um fenômeno. Constituem assim as práticas discursivo-materiais que permitem tanto a produção de sentidos quanto as materializações correspondentes.

\footnotetext{
3 Ver, por exemplo, Alaimo e Hekman (2008), Hird (2009), Hird e Roberts (2011), Kirby e Wilson (2011).
} 
Essas referências não devem ser tomadas aqui como algo que necessariamente unifique ou aproxime os artigos apresentados neste número de Horizontes Antropológicos. Entretanto, sugerimos que podem inspirar a leitura e a produção de novas indagações a partir dos diferentes casos empíricos e recortes teóricos apresentados pelas/os autoras/es, caminhando no prosseguimento de muitos diálogos possíveis.

\section{Saberes e intervencõoes e a produção quotidiana de muitas diferencas}

O artigo que dá início a este dossiê, de autoria de Fabíola Rohden, tem como ponto de partida algumas dificuldades analíticas postas em cena por práticas envolvendo transformações corporais e subjetivas, marcadamente diferenciadas por padrões de gênero e sexualidade, e o consumo de recursos biomédicos. Utilizando o mote da crescente promoção dos chamados fármacos pró-sexuais e das cirurgias estéticas no Brasil, aponta para a necessidade de um enquadramento teórico que possa dar conta dos deslizamentos no estabelecimento de fronteiras que evocam categorias como saúde e aprimoramento ou tratamento e consumo. Nessa direção, o trabalho se propõe a analisar criticamente algumas perspectivas fundamentais dos estudos sobre medicalização da sociedade, incluindo as referências, imprescindíveis nesse contexto, aos conceitos de biomedicalização e farmacologização. $O$ objetivo é mostrar como essas noções são valiosas para compreendermos fenômenos associados à promoção e ao consumo de artefatos biomédicos associados ao par saúde/doença, mas exigem a presença de outros recursos analíticos quando nos aproximamos de situações nas quais o aprimoramento torna-se uma chave fundamental. Além disso, se atentarmos para a forma com a qual as pessoas têm se relacionado com esses recursos, evidente nas narrativas públicas sobre os efeitos transformadores nas suas vidas, torna-se necessário também incluir na reflexão uma discussão acerca dos modos de subjetivação que estão sendo produzidos. Essas questões, de certa forma, podem ser entendidas como instrumentos de problematização também das variadas outras situações empíricas apresentadas nos outros artigos deste volume.

Seguem-se quatro trabalhos que discutem os diversos modos pelos quais os hormônios ditos sexuais são utilizados, pensados e produzidos. Personagens modernos por excelência, os hormônios sexuais carregam consigo ideais que 
dizem respeito à sexualidade e ao gênero, transitando em searas privadas e públicas, trazendo para a discussão tanto a fluidez que hoje marca os modos de produção e transformação corporal quanto a fixidez de um persistente binarismo sexual.

Livi Faro e Jane A. Russo analisam um conjunto de artigos biomédicos que apresentam resultados de ensaios clínicos nos quais o uso da testosterona em mulheres é testado. Visando a obtenção de uma licença para a comercialização de determinado medicamento, tais pesquisas explicitam a íntima relação entre pesquisadores e indústria. Não se trata, porém, apenas de denunciar uma relação espúria, mas de perceber como o conhecimento produzido na pesquisa biomédica tanto se articula aos ideais que circulam socialmente acerca do gênero feminino, do envelhecimento e de um desempenho sexual ideal - quanto contribui ativamente para sua transformação, incidindo sobre os modos de subjetivação a que se refere o texto de Rohden. O deslizamento entre tratamento e aprimoramento, entre possuir um transtorno e melhorar a "normalidade", torna as fronteiras da prática biomédica estrita extremamente porosas e indefinidas.

Essa mesma porosidade ressurge no artigo de Daniela Manica e Marina Nucci. Tendo como objeto de análise implantes subcutâneos de hormônios e microchips também liberadores de hormônio, as autoras demonstram como tais biotecnologias lidam tanto com políticas públicas voltadas para a saúde reprodutiva em níveis macrodemográficos quanto com o consumo personalizado visando mulheres pertencentes aos estratos superiores da população. A relação entre reprodução e aprimoramento, em especial do desempenho sexual, transforma os hormônios em "drogas de estilo de vida", levando à possibilidade de um uso subversivo, não autorizado pela biomedicina, no qual a divisão sexual binária pode ser desestabilizada.

No artigo de Elaine Reis Brandão e colegas surge um outro "personagem hormonal" (um tipo de progesterona sintética), cuja "carreira" seguirá caminhos diversos da testosterona analisada pelos artigos anteriores. Trata-se de um fármaco conhecido como "pílula do dia seguinte", que recebe, entre os/as médicos/as e profissionais de saúde, a denominação de contracepção de emergência, já que deve ser ingerido após a relação sexual. Apesar de seu uso ter sido autorizado no país em 1996, pesa, entretanto, sobre ele uma condenação moral que as autoras buscam investigar através de uma pesquisa com farmacêuticos e balconistas de farmácias. Por um lado o fármaco implica a negação 
de uma prevenção racional tal como é propugnada pelas normas sanitárias visando o planejamento da gravidez e a proteção contra doenças sexualmente transmissíveis. Por outro aponta para um agenciamento feminino que contraria preceitos morais, sociais, de gênero e de classe. Nos dois casos estão em jogo disputas morais em torno da sexualidade feminina, em especial no que tange a mulheres jovens e pobres.

Ainda focalizando o personagem hormônio, Lucas Tramontano discute em seu texto o modo como o conhecimento biomédico estabiliza o binarismo sexual através de uma concepção profundamente "generificada" dos hormônios. Calcando seus argumentos nas formulações de Fleck sobre a ciência dos manuais, Tramontano analisa o modo de apresentação dos hormônios sexuais em dois manuais de fisiologia utilizados atualmente nos cursos de graduação em saúde. Argumenta que, contrariando a visão bioquímica dos hormônios como substâncias mutáveis e em constante transformação, os manuais de fisiologia buscam, através de esquemas e ilustrações, construir tipos rigidamente definidos de moléculas, além de fronteiras claras entre elas, de modo a produzir/reproduzir a fixidez da polaridade masculino/feminino.

A relação entre fluidez e fixidez reaparece nos textos de Wagner Xavier Camargo e Cláudia Samuel Kessler sobre gênero, sexualidade, tecnologia e performance no esporte, e de Mariana Álvarez Broz sobre trajetórias de vida de pessoas transmasculinas na Argentina contemporânea. Camargo e Kessler focalizam os esportes de alto rendimento, em que a divisão binária de gênero institui uma separação que é cada vez mais questionada por situações de pessoas "em trânsito" que desafiam as expressões convencionais de gênero. Apontando a existência de sistemas paralelos ao mainstream esportivo, os autores discutem como a presença de corpos dissonantes contrapõe-se às fronteiras de padrões instituídos colocando questões para o sistema esportivo convencional.

Em seu artigo, Álvarez Broz traz uma etnografia realizada junto a pessoas transmasculinas de Buenos Aires. Através de relatos autobiográficos de seus informantes examina os paradoxos que cercam o par visibilidade/invisibilidade para essas pessoas. A partir de contextos diversos, a escolha entre visibilizar-se enquanto pessoa trans ou passar despercebido (invisível) como um homem a mais não é simples e pode envolver algum grau de sofrimento e desorientação. A partir desse e de outros paradoxos com que convivem as pessoas transmasculinas, a autora traz contribuições importantes para a discussão 
teórica acerca das diferentes masculinidades, hegemônicas e subalternas, com as quais convivemos, e da própria ideia de produção/fabricação do gênero.

Marcelle Jacinto da Silva, Antonio Cristian Saraiva Paiva e Irlena Maria Malheiros da Costa, por sua vez, focalizam a construção propriamente corporal do gênero a partir de uma pesquisa em sites e blogs da internet que tratam da cirurgia plástica vaginal, referida como "embelezamento íntimo". Inicialmente voltada para a correção de problemas funcionais, a cirurgia plástica da genitália feminina é cada vez mais buscada com o intuito de "corrigir imperfeições", levando à fabricação do que seria uma vagina esteticamente perfeita, ou ideal. Trata-se, portanto de perceber a vagina como mais um território de aprimoramento de si.

Já Carlos Eduardo Henning lida com a construção de um novo ator social, o "idoso LGBT", associado ao florescimento recente de um campo de investigação do processo de envelhecimento da chamada população LGBT. Buscando construir um mapa das principais polêmicas e embates teóricos que constituem esse campo, em especial nos Estados Unidos, o autor argumenta que o surgimento de uma "gerontologia LGBT" é concomitante à constituição da noção de velhice homossexual e, mais recentemente, velhice LGBT. Seus desdobramentos no sentido da constituição de políticas públicas são examinados no contexto da produção desse novo ator social. É importante chamar a atenção para o fato de que a concepção de uma "boa velhice", que fundamenta a gerontologia de modo geral, se articula a questões abordadas nos artigos anteriores: de um lado o papel da biomedicina na sustentação de determinados ideais corporais e subjetivos e, de outro, a fluidez das fronteiras entre aprimoramento e tratamento.

$\mathrm{O}$ artigo de Marina França focaliza a aprendizagem da prostituição entre jovens prostitutas da zona boêmia de Belo Horizonte. Através de uma etnografia sensível e afiada, França analisa a transmissão de regras e modos de trabalho entre gerações de prostitutas, incluindo o desenvolvimento de habilidades exigidas na prática sexual e no atendimento ao cliente. Através de um "trabalho emocional" e de uma "educação da atenção", a prostituta aprende a valorizar o carinho e a pessoalidade, bem como a controlar a relação que se estabelece com o cliente. $\mathrm{O}$ artigo aproxima-se dos trabalhos anteriores ao levantar o importante aspecto de uma "pedagogia" ou um "aprendizado prático" - que envolvem transformações corporais e subjetivas - na construção dos atores sociais. 
Os trabalhos comentados até aqui focalizam, de algum modo, as micropolíticas do corpo e do gênero tal como se realizam em diversos campos e em diferentes níveis da vida em sociedade. O artigo de Maria das Dores Campos Machado finaliza nosso dossiê com uma importante reflexão macropolítica acerca dos embates que cercam a moral sexual na sociedade brasileira contemporânea, trazendo à baila uma articulação inesperada entre teorias produzidas no âmbito das ciências sociais e posições políticas conservadoras. Calcado na etnografia de duas audiências públicas realizadas na Câmara Federal, além da votação do Estatuto da Família realizada na comissão especial instituída para discutir proposta apresentada à casa legislativa, todas em 2015, o trabalho de Machado examina a participação dos segmentos religiosos pentecostais nas disputas morais que ocorrem no campo político stricto sensu. Seguindo proposta de Carolina Ivanescu, refere-se à "religiosização" da política, e chama a atenção para a reconfiguração do discurso dos atores pentecostais, que se apropriam parcialmente do construtivismo social para explicar as sexualidades alternativas ao padrão hegemônico no ideário cristão. Segundo sua hipótese, tal reconfiguração discursiva resulta das circunstâncias políticas criadas a partir da redemocratização do país e, mais especialmente, da política de aproximação do Estado brasileiro com os movimentos feministas e LGBT.

\section{Producão de conhecimentos e diversidades na antropologia}

Este número de Horizontes Antropológicos também conta com duas entrevistas realizadas com uma antropóloga e um antropólogo eminentes de diferentes gerações e tradições que nos fazem refletir sobre os vários sentidos da produção etnográfica em meio a distintas trajetórias intelectuais e engajamentos políticos. Inicialmente temos a entrevista com Amade M'charek conduzida por Larissa Costa Duarte e Lucas Riboli Besen. M'charek é a primeira titular da cadeira de Antropologia da Ciência da Universidade de Amsterdã e tem se notabilizado por seu trabalho acerca da interação entre pesquisas genéticas e o debate em torno da diversidade. Além disso, seus artigos retratam, por vezes via o recurso da autoetnografia muito bem situada e instigante, seus posicionamentos enquanto pesquisadora comprometida com as discussões em torno de raça, migração, gênero e sexualidade. Seu trabalho está começando a ser lido 
no Brasil e acreditamos que tem um grande potencial na produção de interlocuções acerca de como raça, gênero, nacionalidade, por exemplo, interagem nas nossas sociedades, muitas vezes por meio de recorrentes referências à produção científica. A apropriação que faz do conceito de objetos dobrados, de Michel Serres, para entender o jogo entre presenças e ausências da raça na história da genética, pode ser tomada aqui como inspiração para pensarmos a respeito dos argumentos produzidos e/ou atualizados contemporaneamente acerca de gênero e sexualidade. Na leitura dos artigos que seguem, pode nos servir como guia para reconhecermos as situações e as tensões nas quais enquadramentos mais ou menos biologizantes ou naturalizantes são impostos ao entendimento das diferenças. E nessa linha não apenas vetores como raça, gênero ou sexualidade, mas também geração, classe social, religião compõem um cenário bastante complexo de interações, como podemos ver por meio das etnografias apresentadas.

O diálogo de Duarte e Bessen com M'charek, especialmente quando discutem as relações entre a produção de conhecimento na antropologia e as distâncias provocadas por diferentes contextos nacionais e linguísticos e quando problematizam o entendimento de noções como raça na ciência e nos movimentos sociais, mais uma vez nos remete para a necessidade de também apresentarmos esta publicação como parte de um esforço ao mesmo tempo científico ou acadêmico e político. Como já apontamos, a firmeza das críticas à ciência, particularmente advindas do feminismo, tem sido uma das bases a partir da qual tem se produzido um processo de crítica social absolutamente necessário no desenvolvimento de tecnociências mais socialmente responsáveis. Ao mesmo tempo em que partilhamos dessa perspectiva analítica, entendemos que faz parte do nosso compromisso acadêmico e social reforçar os espaços para a produção e divulgação dessas discussões. Por isso, novamente salientamos a relevância no atual contexto, no qual os debates parecem se tornar cada vez mais restritos e difíceis, de sustentar as investigações e reflexões analíticas acerca de como gênero, sexualidade, raça e outras tantas diferenças vêm sendo produzidas.

A segunda entrevista foi realizada por Patrícia Kunrath Silva com George Marcus, chefe do Departamento de Antropologia da Universidade da Califórnia em Irvine (UCI) e um dos mais proeminentes antropólogos norte-americanos na atualidade. Além de nos brindar com o relato sobre sua trajetória de formação e interesse pela antropologia, nos conduz a entender melhor 
como Marcus passou a se concentrar na reflexão sobre a etnografia e a produção do conhecimento enquanto gêneros narrativos a partir da experiência de ensinar o fazer etnográfico às/aos suas/seus estudantes. Segundo ele, foi nesta fase que "a escrita se tornou o meio da minha reeducação em antropologia após ter passado por departamentos famosos, mas não inspiradores".

Especialmente no contexto deste volume cabe chamar a atenção para dois pontos em particular. O primeiro se refere ao destaque que Marcus concede aos estudos sobre ciência, em vários momentos da entrevista, a começar com sua parceria com Michael Fischer, importante referência nessa área. De acordo com o pesquisador os estudos da ciência "se tornaram [...] a tendência dominante para pensamentos inovadores em antropologia desde o período de Writing culture". Essa percepção se insere no contexto de preocupações de Marcus em relação à natureza participativa ou colaborativa do trabalho antropológico e também no que diz respeito às discussões sobre o desenvolvimento de uma antropologia aplicada. $\mathrm{O}$ segundo ponto diz respeito à menção que faz sobre alteridade e raça, assuntos também em destaque na conversa com M'charek. Quando questionado por Kunrath acerca do estudo da própria cultura norte-americana, Marcus relata que trabalhar nos Estados Unidos e sobre a cultura daquela sociedade tem sido algo impróprio e não recomendado às/aos estudantes, em virtude de uma relação complicada com a alteridade. Afinal, segundo ele, "temos que lembrar que a antropologia é imperial: quem é alteridade? São indígenas, imigrantes..., não nós". E continuando afirma que um dos grandes problemas para a antropologia "foi largar os estudos de raça e se tornar apenas o estudo da cultura, especialmente na sociedade norte-americana. Apagar o racismo na precoce antropologia norte-americana resultou em colocar os estudos de raça de lado por um bom tempo. Foi um erro em retrospectiva."

Essas considerações sobre a relevância dos estudos sobre ciência e acerca da importância dos estudos sobre raça, além de uma menção aos estudos feministas, não só dialogam com as ponderações de M'charek como também ajudam a reforçar a proposta de debate em curso nesta publicação. Algo que tem se tornado evidente para alguns pesquisadores/as, mas que sempre esteve óbvio na realidade da vida quotidiana a partir de posições situacionalmente distintas, inclusive na academia, são as formas reiteradas de evocação da raça e do sexo como justificativas naturalizantes na e para a produção de conhecimento. 
Começamos esta apresentação ressaltando a diversidade de saberes e intervenções acionados nas análises retratadas neste volume e apontamos para muitos contrastes e aproximações possíveis. Porém, para finalizar, torna-se imperativo chamar a atenção para a recorrência, retratada nestes trabalhos, de que continuamos assistindo a renovadas tentativas de conceber e demarcar as diferenças de gênero e sexualidade, assim como raça, em termos dicotômicos e cristalizados. Como estes estudos têm mostrado, se de um lado temos, como sempre tivemos, tentativas inovadoras e corajosas de redesenhar e assumir as potencialidades do humano para além dos padrões restritivos e discriminatórios, por outro, reforçam-se os argumentos em nome dos essencialismos doutrinários de diferentes ordens. Além disso, é importante assinalar que a afirmação de fronteiras fluidas e porosas, como antídoto contra a fixidez das dualidades essencializadas, também marca tanto um viés contemporâneo da biomedicina, em sua proposta de transformação e conformação dos corpos através da biotecnologia, quanto a exigência contemporânea de um self plástico, flexível e mutável visando a melhor adaptação possível a uma concepção neoliberal de trabalho e desempenho. Como antropólogas engajadas em um projeto que reconhece a imprescindível conexão entre a produção de conhecimento e o compromisso com a ética e a justiça, apostamos que as reflexões trazidas à cena podem nos ajudar a enfrentar esses dilemas.

Por fim, cabe fazer referência à imagem escolhida para a da capa deste volume, que reproduz um detalhe da parte central do tríptico $O$ jardim das delícias terrenas de Hieronymus Bosch, pintado entre o final do século XV e o início do século XVI (sua datação é imprecisa), hoje no Museu do Prado. Sendo interpretado ora como uma advertência moral contra os pecados e a luxúria de uma humanidade degradada, ora como a celebração de um paraíso perdido, o tríptico de Bosch, como boa parte de sua obra, contém um conjunto de figuras e elementos perturbadores, cujo simbolismo os/as estudiosos/as buscam desvelar. A obra é marcada pela ausência de uma clara diferenciação corporal entre homens e mulheres e pela presença de uma sexualidade difusa e múltipla. As cores suaves e as cenas ao mesmo tempo poéticas e bizarras lembram uma atmosfera de sonho que, segundo André Breton, prefigura o surrealismo do século XX. Pretendemos, com essa imagem, remeter à discussão contemporânea acerca da fluidez e dos deslizamentos entre os corpos e os gêneros, bem como às tensões morais a eles associadas. 


\section{Referências}

ABRAHAMSSON, S. et al. Living with omega-3: new materialism and enduring concerns. Environment and Planning D: Society and Space, London, v. 33, n. 1, p. 4-19, 2005.

ALAIMO, S.; HEKMAN, S. Material feminisms. Bloomington: Indiana University Press, 2008.

BARAD, K. Posthumanist performativity: toward an understanding of how matter comer to matter. Signs: Journal of Women in Culture and Society, Chicago, v. 28, n. 3, p. 801-831, 2003.

BARAD, K. Meeting the universe halfway: quantum physics and the entanglement of matter and meaning. Durham: Duke University Press, 2007.

BIRKE, L. Women, feminism and biology: the feminist challenge. Brighton: Harvester, 1986.

BLEIER, R. Science and gender: a critique of biology and its theories on women. New York: Teachers College Press, 1997.

BUTLER, J. Bodies that matter. New York: Routledge, 1993.

FAUSTO-STERLING, A. Myths of the gender: biological theories about women and men. New York: Basic Books, 1992.

FLECK, L. Gênese e desenvolvimento de um fato científico. Belo Horizonte: Fabrefactum, 2010.

HARAWAY, D. Saberes localizados: a questão da ciência para o feminismo e o privilégio da perspectiva parcial. Cadernos Pagu, Campinas, n. 5, p. 7-41, 1995.

HARAWAY, D. The Haraway reader. New York: Routledge, 2004.

HIRD, M. J. Feminist engagements with matter. Feminist Studies, College Park, v. 35, n. 2, p. 329-346, 2009. 
HIRD, M. J.; ROBERTS, C. Feminism theorises the nonhuman. Feminist Theory, London, v. 12, n. 2, p. 109-117, 2011.

JASANOFF, S. States of knowledge: the co-production of science and social order. New York: Routledge, 2004.

KIRBY, V.; WILSON, E. A. Feminist conversations with V. Kirby and E. A. Wilson. Feminist Theory, London, v. 12, n. 2, p. 227-234, 2011.

LAW, J. After method: mess in social science research. New York: Routledge, 2004.

LAW, J.; MOL, A. (Ed.). Complexities: social studies of knowledge practices. Durham: Duke University Press, 2002.

MOL, A. Ontological politics. A word and some questions. The Sociological Review, Keele, v. 47, n. esp., p. 74-89, 1999.

MOL, A. The body multiple: ontology in medical practice. Durham: Duke University Press, 2002.

MOL, A.; LAW, J. Embodied action, enacted bodies. The example of hypoglycaemia. Body \& Society, v. 10, n. 2-3, p. 43-62, 2004.

OUDSHOORN, N. Beyond the natural body: an archeology of sex hormones. London: Routlegde, 1994.

ROHDEN, F. et al. Antropologia das ciências no Brasil: dobras reflexivas. In: FONSECA, C. et al. (Org.). Antropologia da ciência e da tecnologia: dobras reflexivas. Porto Alegre: Sulina, 2016. p. 15-32. 